\title{
Application of a Novel Patient - Specific Rapid Prototyping Template in Orthopedics Surgery
}

\author{
Sheng Lu, Yong-qing $\mathrm{Xu}$ and Yuan-zhi Zhang \\ Department of Orthopedics, Kunming general hospital, \\ Chengdu military district, PLA, Kunming,
}

China

\section{Introduction}

Conventional surgical handwork requires competences such as dexterity or fine motor skills, which are complemented by visual and tactile feedback. Computer-assisted orthopaedic surgery aims at improving the perception that a surgeon has of the surgical field and the operative manipulation. Bony manipulation such as drilling, chiseling, or sawing can be performed more accurately and implants can be placed more exactly. This reduces the risk of harming the patient intra-operatively by damaging sensitive structures.

CT scans are very suitable for surgical navigation, especially in orthopaedics. The bones can be easily distinguished from any other tissue, and can be easily segmented out. The bones are also the least deformable parts of the body, and therefore the most stable references for navigation, making it possible for different phases of surgical planning and execution to be performed well after the patient imaging. Pre-operative planning is typically done in three orthogonal cross-sectional views made through the CT scan volume.

\section{Application of a novel patient - specific rapid prototyping template in orthopedics surgery}

The rapid prototyping template first apply in the hip and knee athroplasty and then apply in the spine surgery. But the limitation of template design and produce technique, the authors introduced and validated a novel rapid prototyping templates in the clinical setting. Report on their experience with spinal pedicle screw placement, [1,2] placement of C2 laminar screws, [3] accurate prosthesis implantation in hip resurfacing arthroplasty, etc using a novel computer- assisted drill guide template.

\subsection{A novel computer- assisted rapid prototyping drill guide template for spinal pedicle screw placement}

Spinal Pedicle screw fixation systems provide three-dimensional (3D) fixation in the spine. Compared with conventional hook instrumentation, the clinical advantages of such systems include enhanced correction and stabilization of various deformities, shorter fusion length, more solid and reliable fixation, and no encroachment into the spinal canal. Therefore, pedicle screw fixation systems have gained popularity for internal fixation of fractures, tumors, and deformities of the spine . In spinal pedicle screw insertion, it is important both 
to select the correct size of screw and to place it properly within the pedicle to ensure good anchoring. Manual placement has a high associated rate of unplanned perforation, which is the major specific complication of pedicle screw placement and causes a high risk of bone weakening or lesions of the spinal cord, nerve roots, or blood vessels.

Successful placement of pedicle screws in the cervical spine requires a thorough threedimensional understanding of the pedicle morphology in order to accurately identify the ideal screw axis. Several methods have been explored for precise cervical pedicle screw placement including anatomic studies, image-guided techniques, computer-assisted surgery system, and drill templates. These techniques can be broadly classified into five types: (1) techniques relying on anatomical landmarks and averaged angular dimensions; (2) techniques with direct exposure of the pedicle, e.g. by laminaminotomy; (3) CT-based computer assisted surgery (CAS), and (4) fluoroscopy-based CAS techniques. (5) Drill template techniques.

The principle of image guidance is to register the patient's pre-operative computed tomography (CT) scans, thus permitting the surgeon to navigate simultaneously within the patient and the CT scan volume. Such navigation systems have shown good clinical results. There are, however, several disadvantages associated with navigation systems. In cases where screws are to be placed in more than one vertebra, it is necessary to perform a separate registration step for each vertebra. Intraoperative registration of bone structures takes up to several minutes, and thus the time taken for the overall procedure is increased compared with a conventional approach. The navigation equipment often requires additional personnel to be present during surgery, and this, together with the increased operating time, leads to a higher risk of intraoperative infection. The navigation equipment is cumbersome and occupies a lot of space in the operating room. Finally, only a few hospitals can bear the costs of sensor or robot-based systems. One way to overcome these drawbacks is the production of personalized templates. These are designed using preoperative CT to fit in a unique position on the individual's bone, and they have carefully designed holes to guide the drill through a pre-planned trajectory.

\subsubsection{A novel patient-specific navigational template for cervical screw placement}

Successful placement of pedicle screws in the cervical spine requires a thorough threedimensional understanding of the pedicle morphology in order to accurately identify the ideal screw axis. The accuracy of computer-assisted screw insertion has been demonstrated recently. The rate of pedicle perforations was $8.6 \%$ in the conventional group and $3.0 \%$ in the computerassisted surgery group in 52 consecutive patients who received posterior cervical or cervicothoracic instrumentations using pedicle screws. [4] Another group has also reported similar results, in which the rate of pedicle wall perforation was found to be significantly lower in the computer-assisted group (1.2\%) than in the conventional group (6.7\%).[5] However, despite advances in instrumentation techniques and intra-operative imaging, successful implementation of posterior cervical instrumentation still remains a challenge.

Considering these difficulties, this study introduces an ingenious, custom-fit navigational template for the placement of pedicle screws in the cervical spine and further validate it in the clinical settings. Based on this technique, the trajectory of the cervical pedicle screws were first identified based on the preoperative CT scan model. The drill template was then patient-specifically designed so that it can keep in close contact with the postural surface of the cervical vertebra in order to provide the best stability for drilling. 
25 patients (14 male, 11 female, age 17-53 years) with cervical spinal pathology included 10 patients with destabilizing cervical spine injuries, 4 patients with cervical spondylotic myelopathy, and 11 patients with basilar invagination requiring instrumentation underwent cervical pedicle screw placement using a novel, patient-specific navigational template technique. According to this technique, a spiral three-dimensional (3-D) CT scan (LightSpeed VCT, GE, USA) was performed preoperatively on the cervical spine of each patient with a $0.625-\mathrm{mm}$ slice thickness and $0.35-\mathrm{mm}$ in-plane resolution. The images were stored in DICOM format, and transferred to a workstation running MIMICS 10.01 software (Materialise, Belgium) to generate a 3-D reconstruction model of the desired cervical vertebra (Fig. 1).

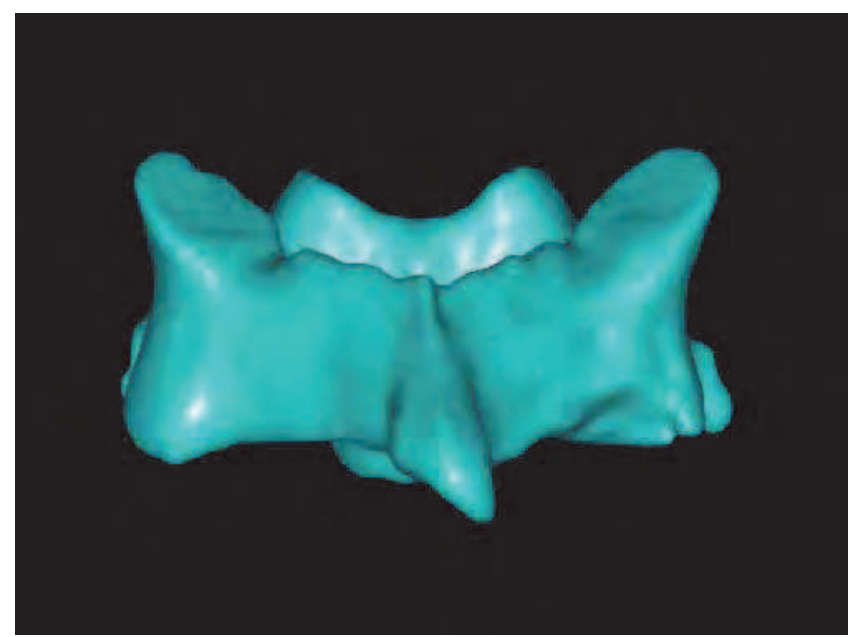

(a)

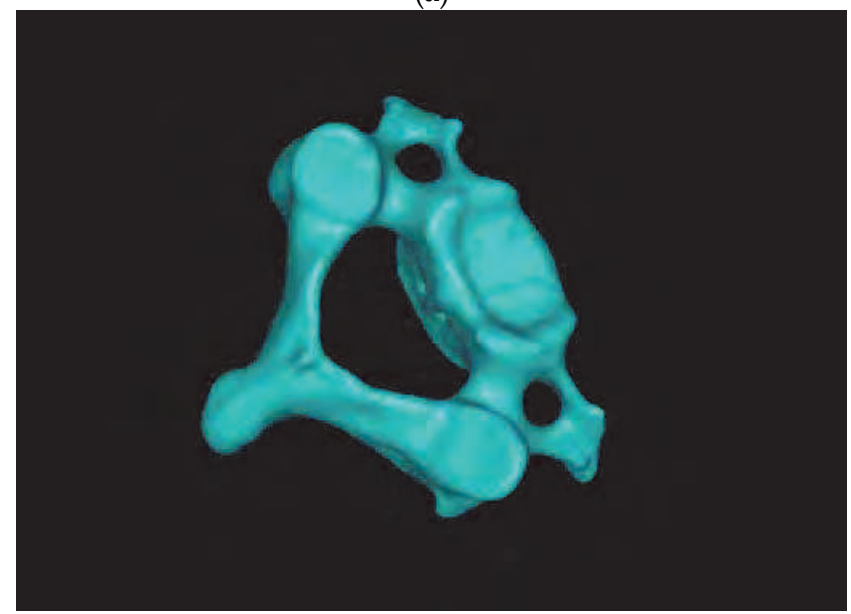

(b)

Fig. 1. 3-D model of the cervical vertebra (C3).

a: posterior view ; b: lateral view 
The 3-D cervical vertebral model was then exported in STL format to a workstation running Reverse Engineer software -UG imageware12.0 (EDS, US), for determining the optimal screw size and orientation. Using the UG Imageware software, the pedicles (left and right pedicle) were projected towards the vertebra and lamina (Fig.2a). As the thickness and cross section of the pedicle vary along its length, the smaller diameter of the elliptical inner boundary of the pedicle's projection was used in determining the maximum allowable dimension for screw diameter (Fig.2b). This diameter was further used to draw a circle and projected between the vertebra and the lamina to obtain the optimal pedicle screw trajectory (Fig.2c,). A 3D vertebral model was reconstructed with a virtual screw placed on both sides(Fig.2d).
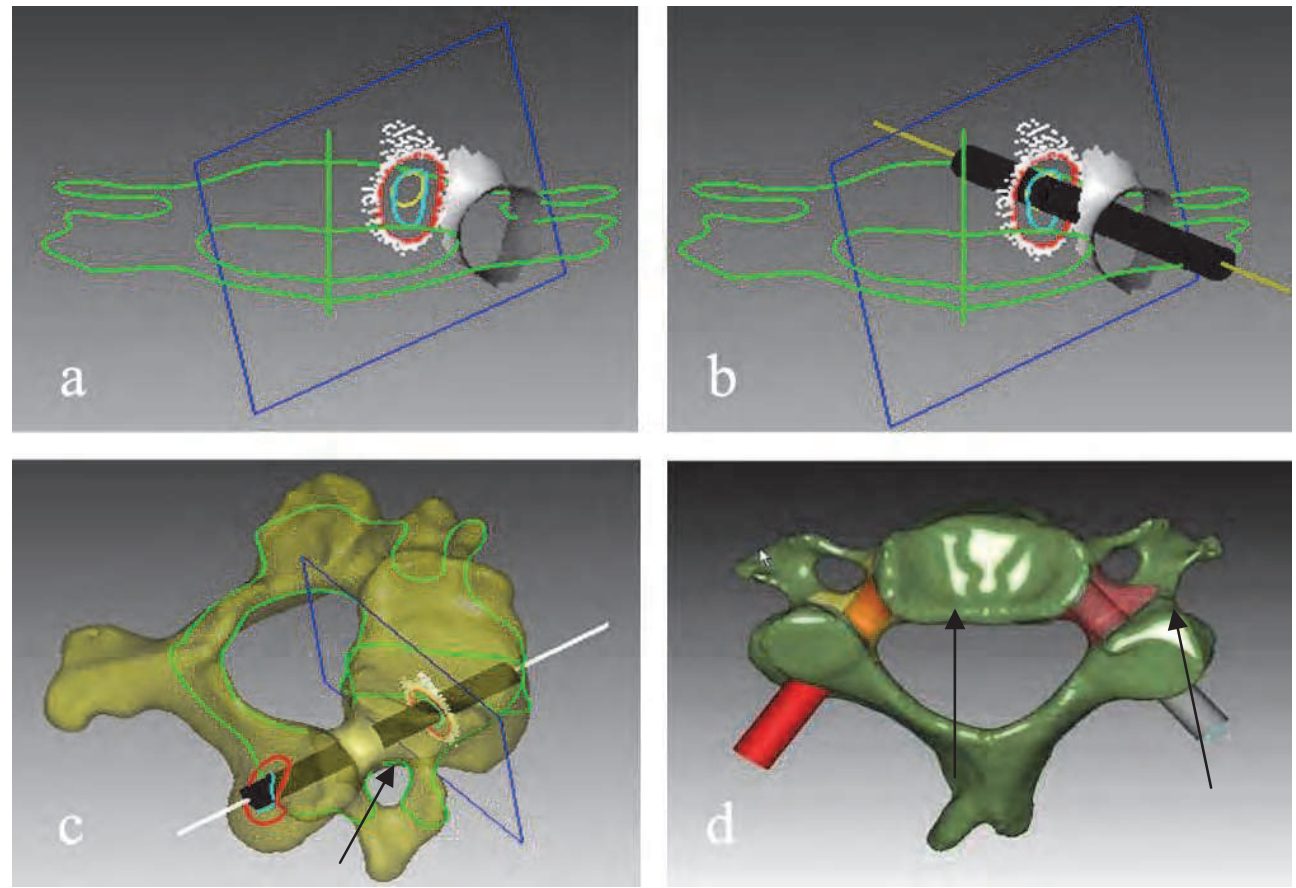

Fig. 2. Analysis of cervical pedicle screw trajectory by the Reverse Engineering software a: Pedicle and its positive projection; b: the best trajectory of pedicle screw projection;c: Pedicle screw channel. (arrow) d: Planned screw trajectory (arrows) 
Following the determination of the optimal pedicle screw trajectory, a navigational template was constructed with a drill guide on either side. The template surface was created as the inverse of the vertebral posterior surface, thus potentially enabling a nearperfect fit. It was also made sure that there was no overlapping of the template onto adjacent segments (Fig.3).

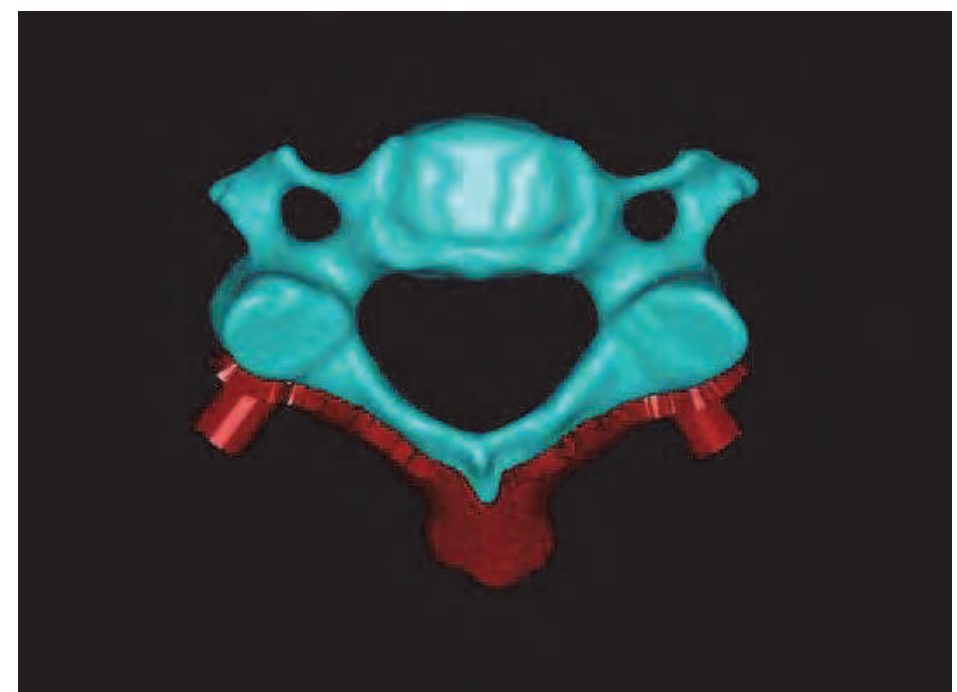

(a)

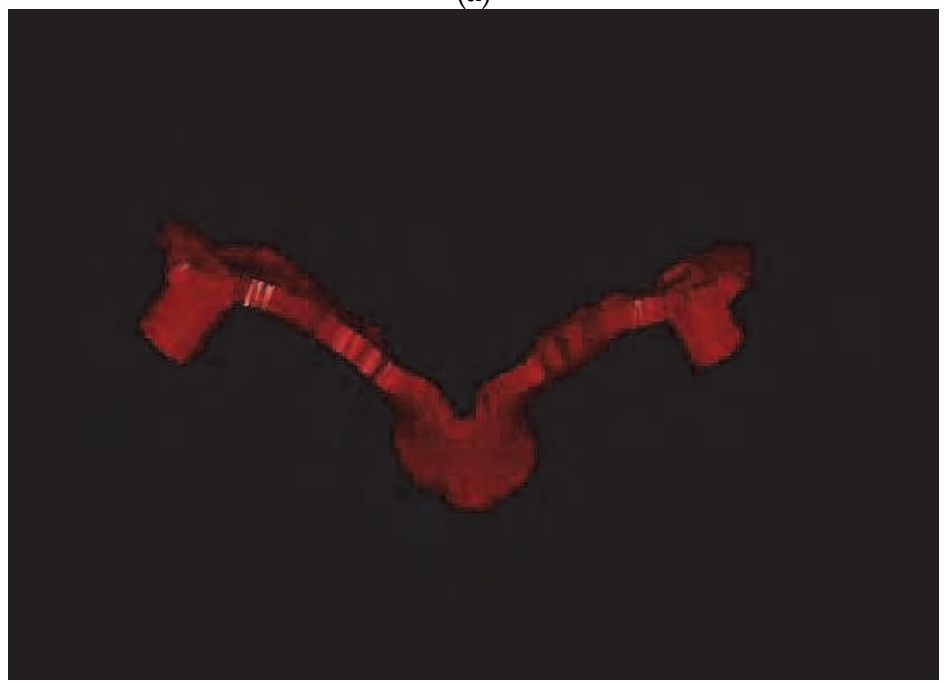

(b)

Fig. 3. Design of the navigational template

a: Navigational template fits with the vertebra perfectly; b: The 3-D computer model of navigational template 
The biomodel of the desired vertbera as well as its corresponding navigational template were produced in acrylate resin (Somos 14120, DSM Desotech Inc, USA) using stereolithography - a rapid prototyping (RP) technique (Hen Tong company, China). The accuracy of the navigational template was examined by visual inspection before surgery. The biomodel of the vertebra and its corresponding template were placed together, and a standard electric power-drill was used to drill the screw trajectory into the biomodel of the vertebra through the template navigation holes. Visual inspection was performed for identifying any violation (Fig.4)

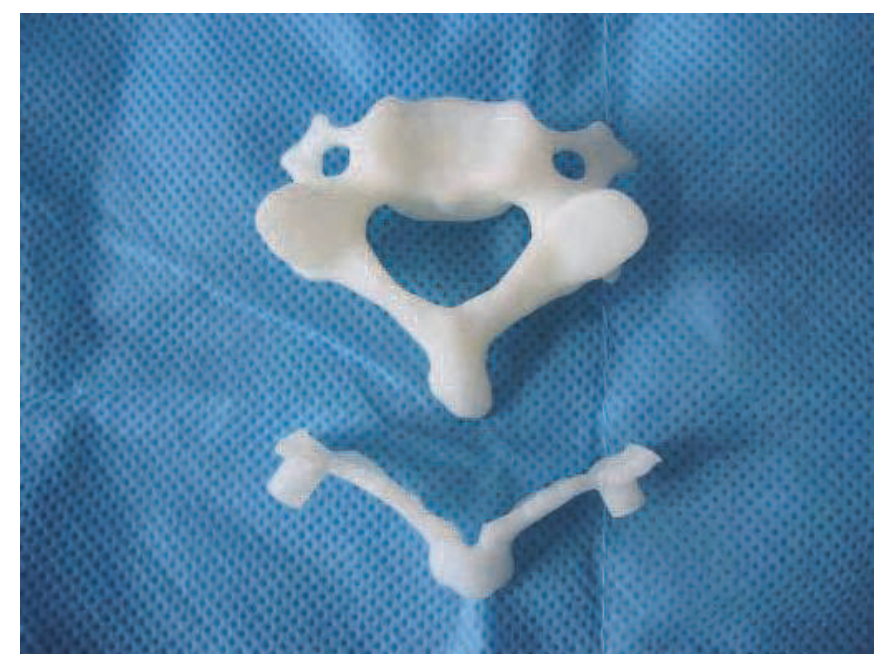

(a)

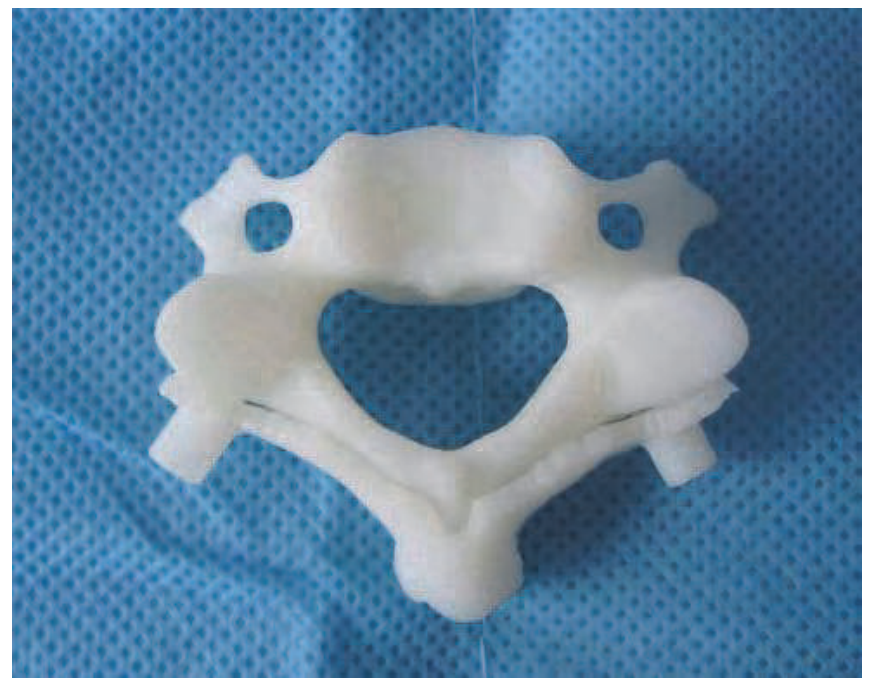

(b) 


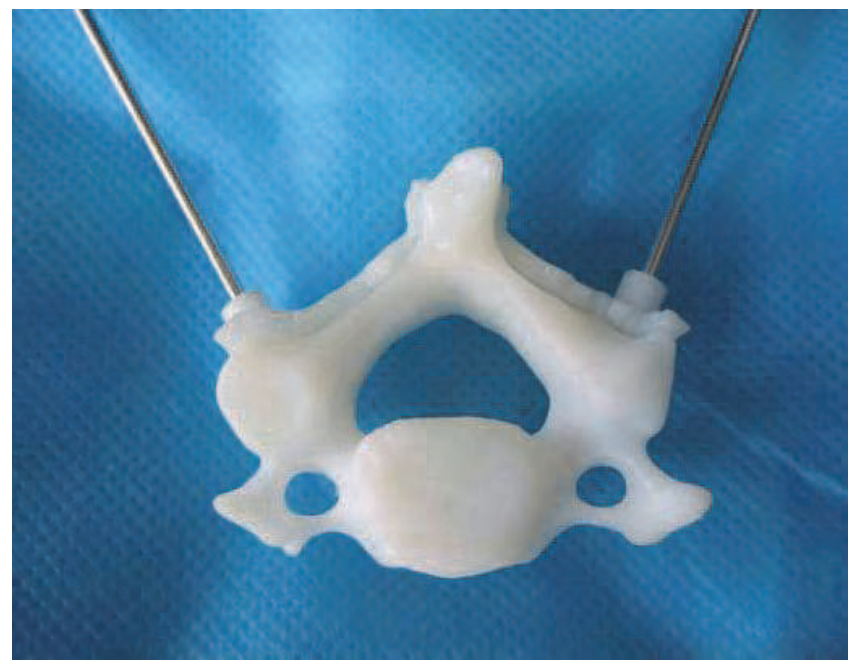

(c)

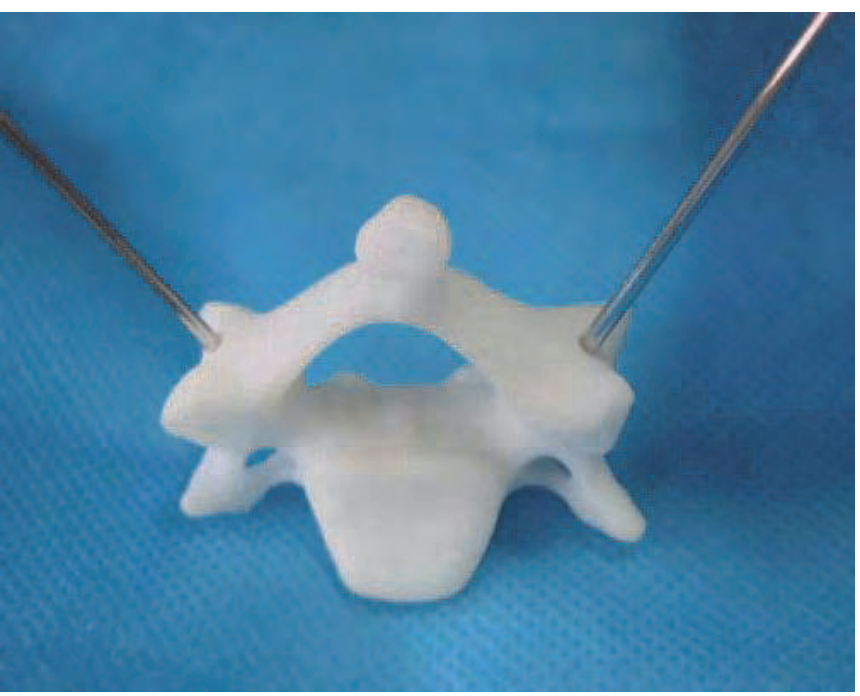

(d)

Fig. 4. The accuracy of the navigational template was examined by visual inspection a: RP model of vertebra and navigational template; b: navigational template fits RP model of vertebra perfectly; $\mathrm{c}$ K wires inserted through navigational template into the pedicles; $\mathrm{d}$ : accuracy of the navigational template examined by visual inspection.

The template was sterilized and used intraoperatively for navigation and for confirming anatomic relationships. For safety reasons, fluoroscopy was performed intraoperatively during drilling and insertion of the pedicle screw on the first 3 patients. For the remaining cases, fluoroscopy was performed only after the insertion of all the pedicle screws, thus 
considerably reducing the exposure time to radiation. After surgery, the positions of the pedicle screws were evaluated using X-ray and CT scan. An axial image, including the whole length of each screw, was obtained, and the medial and lateral deviation of the screw was classified into 4 grades 6 . Grade 0 , no deviation; the screw was contained in the pedicle. Grade 1, deviation less than $2 \mathrm{~mm}$ or less than half of the screw diameter. Grade 2, deviation more than $2 \mathrm{~mm}$ and less than $4 \mathrm{~mm}$, or half to one screw diameter. Grade 3, deviation more than $4 \mathrm{~mm}$, or complete deviation.

The accuracy of the navigational template was examined before operation by drilling the screw trajectories into the vertebral biomodels. Each navigational template was found to be fitting to its corresponding vertebral biomodel appropriately without any free movement, and the $\mathrm{K}$ wires were found to be inserted through the drill hole through the pedicle and into the desired vertebra without any violation as found by visual inspection.

During the operation, it was easy to find the best fit for positioning the template manually, as there was no significant free motion of the template when it was placed in position and pressed slightly against the vertebral body. As such, the navigational template fulfilled its purpose for use as in situ drill guide.

A total of 88 screws were inserted into levels C2-C7 with 2-6 screws on each patient. Of these pedicle screws, 71 were in Grade- 0,14 in Grade-1, 3 in Grade-2, and no screw was in Grade-3. None of the cases had complications caused by pedicle perforation and especially there were no injury to the vertebral artery or to the spinal cord, nor was there a need for revision of pedicle perforation in any of the cases.

In this study, cervical pedicle abnormality existed in five patients. The pedicles (four C2 and one C7) of these patients were very narrow with a minimum diameter of $3.5 \mathrm{~mm}$. Screws of relatively smaller diameter (3-mm) were chosen for these patients accordingly, and were placed inside pedicles accurately using navigational templates. (Fig.5)

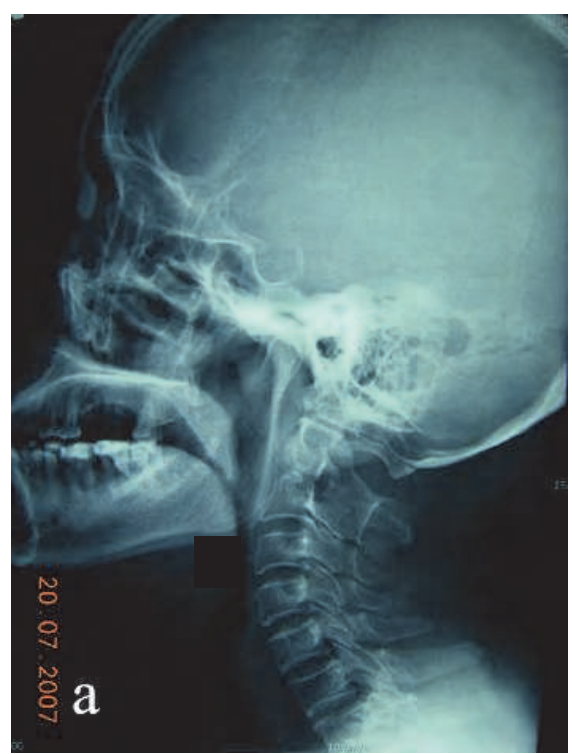

(a)

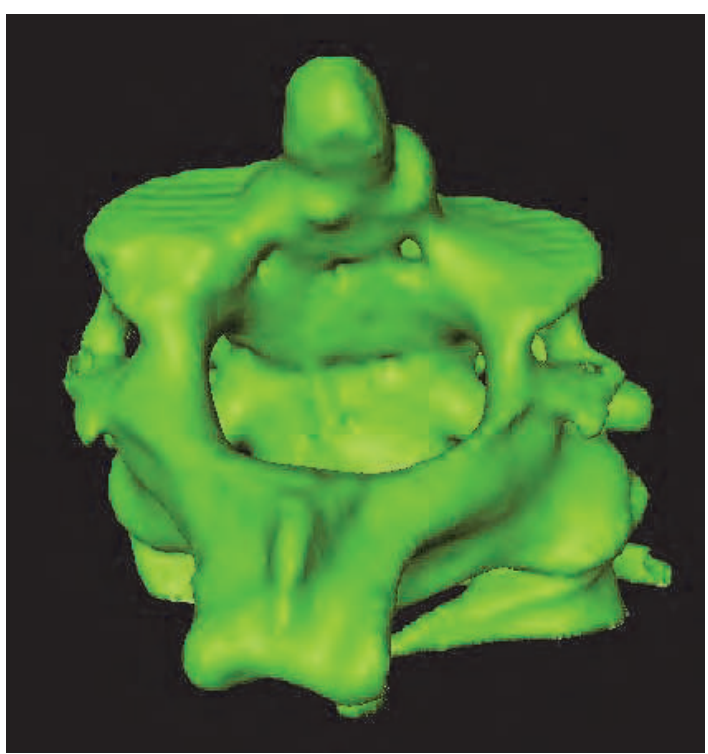

(b) 


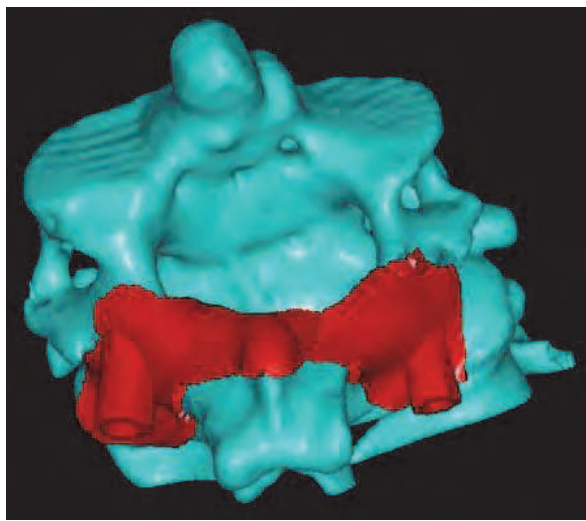

(c)

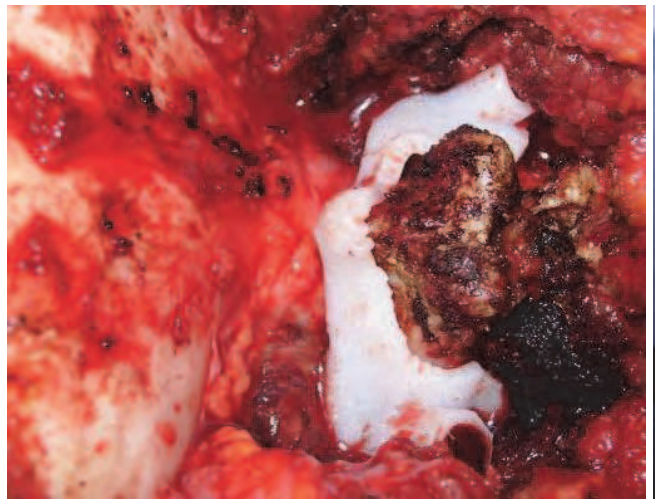

(e)

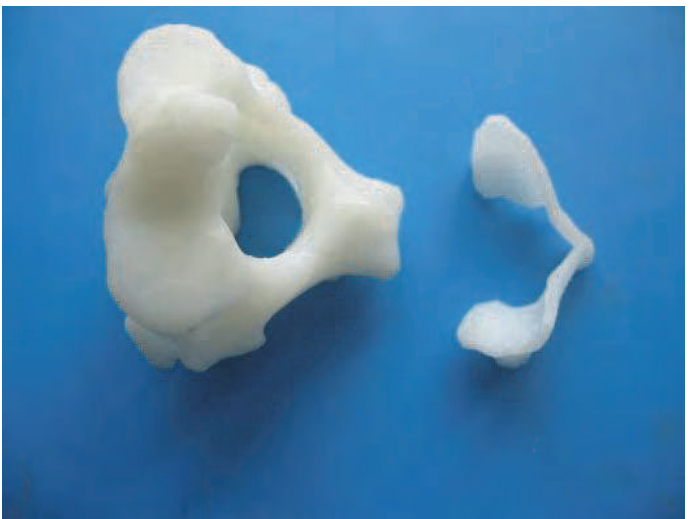

(d)

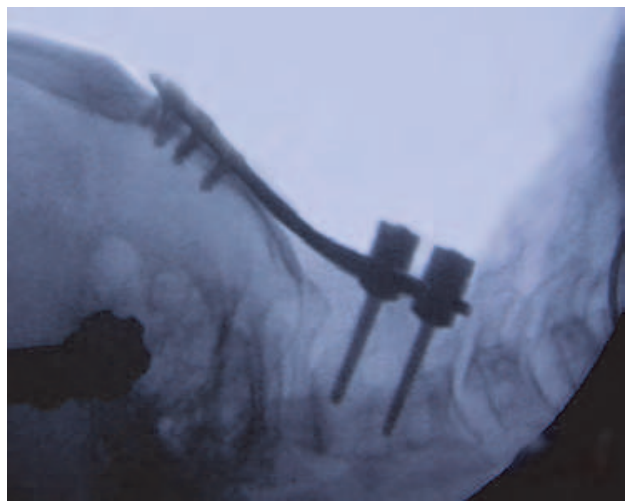

(f)

Fig. 5. A female patient was diagnosised of basilar invagination, trans-C2 Pedicle screw Occipto-Cervical Fusion was done; In this case the C2,3 fusion was observed and the diameter of left $\mathrm{C} 2$ pedicle was only $3.5 \mathrm{~mm}$, the $\mathrm{C} 2$ pedicle screw was inserted using the navigational template;

a: the X-ray shows atlantoaxial dislocation; d: 3-D model of C2,3; b,c: Pedicle screw trajectory and design of the C2 navigational template; $\mathrm{d}$ : RP model of $\mathrm{C} 2,3$ and navigational template, e: the navigational template fit the posterior part of $\mathrm{C} 2$ perfectly; f: fluoroscopy show good positioning of pedicle screw;

In another case, the pedicle was extremely narrow in level C2 with a minimum diameter of only $1.5-\mathrm{mm}$ and therefore the $\mathrm{C} 2$ cervical fixation was not performed. The $\mathrm{CT}$ data showed congenital fusion between C2 - C3 and therefore pedicle screw fixation was successfully performed on level C3 using the drill template.

By using this novel, custom-fit navigational template, the operation time has been considerably reduced. On an average, each vertebral pedicle screw insertion took about 80 seconds. Fluoroscopy was required only once after the insertion of the entire pedicle screws, which has considerably reduced the duration of radiation exposure to the members of the surgical team. Currently the production time for RP model is about 2 days and the cost is 
about $\$ 50$ per vertebral level. The production time can be brought down to 1 day and the cost can be reduced to $\$ 20$ if the RP model of the vertebra is not needed.

\subsubsection{A novel patient-specific navigational template for thoracic pedicle placement}

Most studies have shown that the rates of misplacement for the free-hand technique are usually between $28 \%$ and $43 \%$, while only a few studies have shown rates of less than $5 \%$. Hence, the screw breach rate may be dangerously high when the anatomy is altered as in scoliosis. Lonner et al. [6] suggested that there should be a considerable learning curve for using the pedicle screws in scoliosis surgery to avoid complications. The need for improved accuracy and consistency in the placement of thoracic pedicle screws has led to investigations on the application of computer-navigated spine surgery. Computer-assisted pedicle screw installation allows for an increased accuracy in using screws, thus decreasing the incidence of misplaced screws. Considering these difficulties, surgeons must use whatever techniques they find helpful to create a safe environment when placing thoracic pedicle screws into the deformed pediatric spine.

16 patients (12 females, 4 males, age 5-18 years) with scoliosis (14 adolescent idiopathic scoliosis, 2 congenital scoliosis) undergoing spinal deformity correction surgeries using posterior pedicle screw instrumentation of the thoracic spine formed the study group. Before the operation, a spiral three-dimensional (3-D) CT scan (LightSpeed VCT, GE, USA) was performed on the thoracic spine of each patient with $0.625 \mathrm{~mm}$ slice thickness and 0.35 $\mathrm{mm}$ in-plane resolution. The images were stored in DICOM format and transferred to a workstation running MIMICS 10.01 software (Materialise company, Belgium) to generate a 3-D reconstruction model for the desired thoracic vertebra (Fig. 6a). The 3-D vertebral model

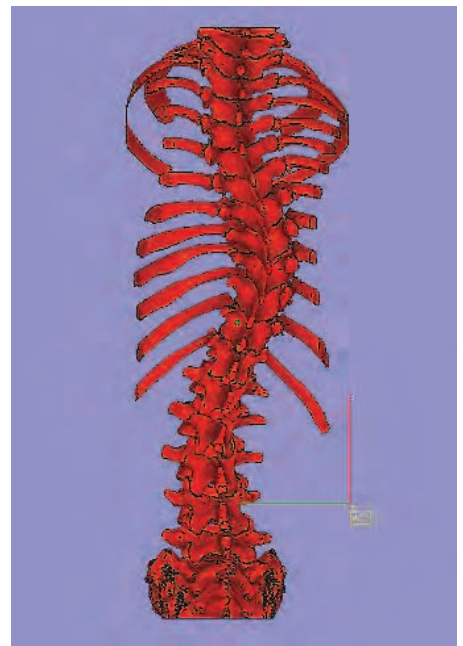

(a)

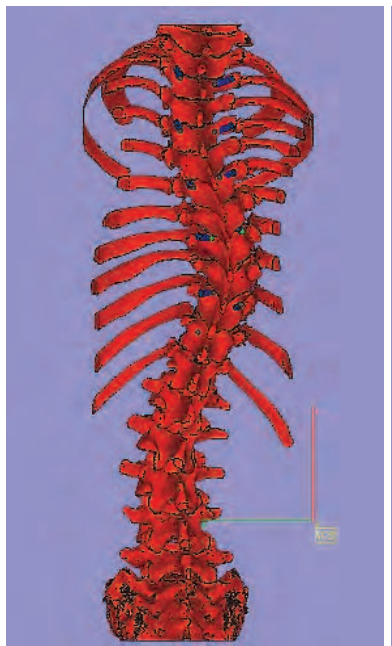

(b)

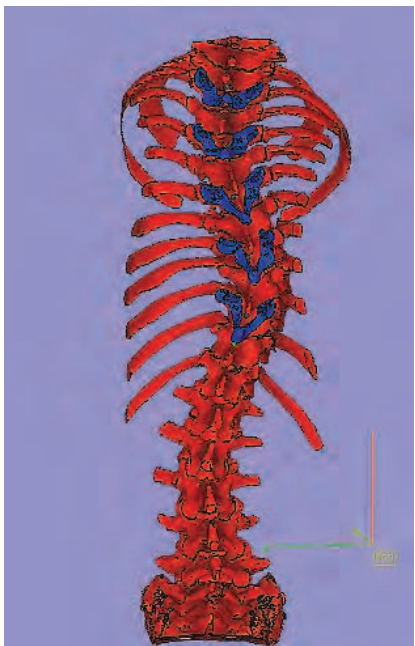

(c)

Fig. 6. Trajectory of the pedicle screw and design of the navigational template a: Three-dimensional model of the scoliosis vertebra; b: Planned screw trajectory (blue). c: The navigational template was created as the inverse of the posterior vertebral surface fitting with the vertebra perfectly. 
was then exported in STL format and opened in a workstation running Reverse Engineering (RE) software UG imageware12.0 (EDS, USA) to determine the optimal screw size and orientation. A screw with a diameter of $5 \mathrm{~mm}$ was placed virtually into the 3-D spinal model on both sides. The virtual screw's entry point and the trajectory were placed at the center of the pedicle without violating the cortex.

\section{Pre-operative Planning}

According to the type of scoliosis, the fusion level is determined, and the instrumentational vertebra is chosen. The design and development of the drill template for each vertebra are also made according to the instrumentational vertebra. The vertebral rotation, axes, length, and diameter of the pedicle were measured from the pre-operative CT scan. Thus, the length and diameter of every pedicle screw were decided upon before operation. The concave periapical (T5-8) pedicles are often deformed and are considered to be the most difficult area to work on during pedicle screw placement $[3,27-29]$. If the pedicle is very narrow, an inout-in technique can be chosen. (Fig 7).

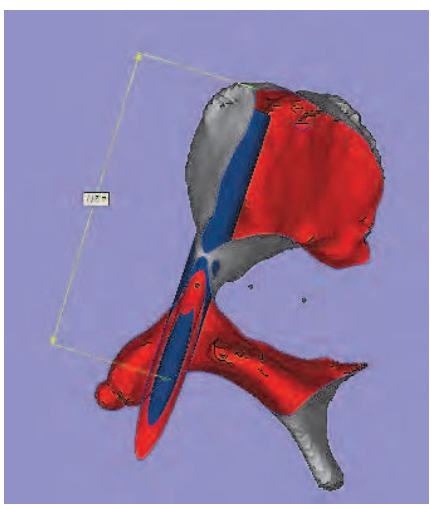

(a)

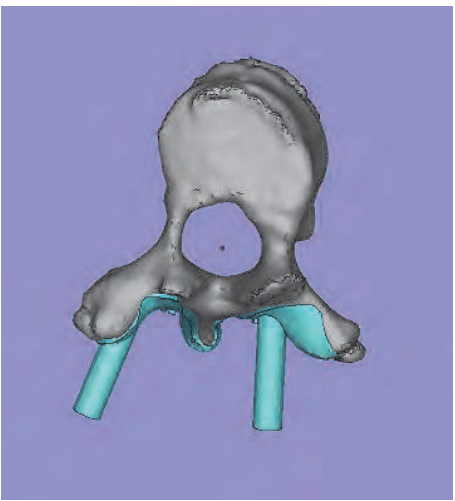

(c)

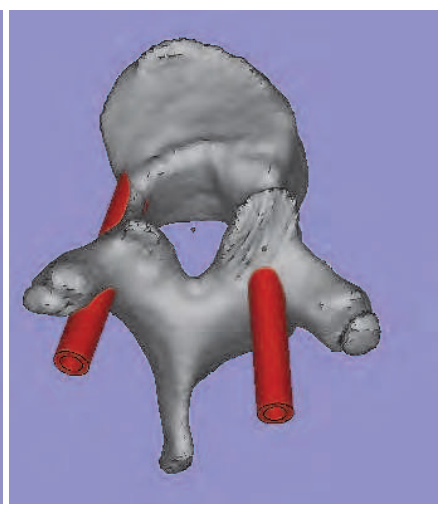

(b)

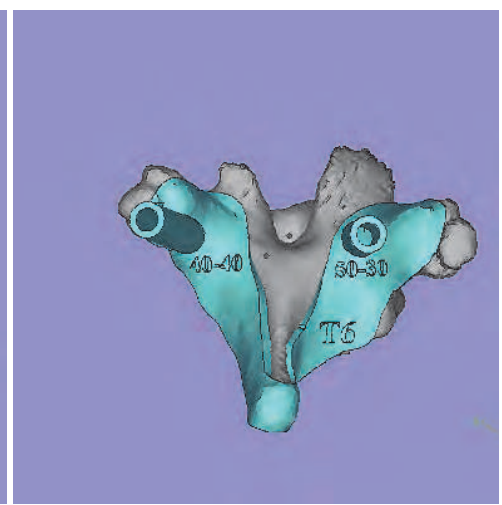

(d) 


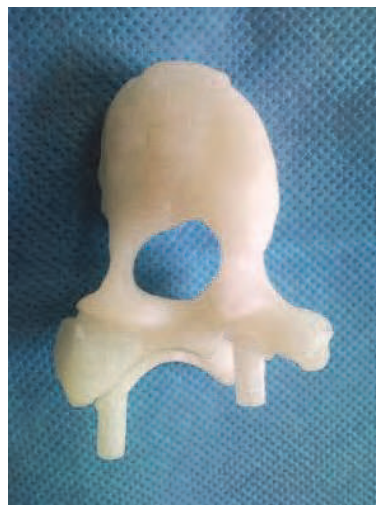

(e)

Fig. 7.3D reconstruction of a single vertebra and the biomodel of the drill template a: The best trajectory of the pedicle screw and measurement of the length of the pedicle; $b$ : In-out-in technique in the concave side; c: The navigational template fits the vertebra perfectly; d: The template can show the location, diameter, and length of the pedicle screw; e: The navigational template fits the RP model of the vertebra very well.

\section{Operation procedure}

The spine was exposed subperiosteally on both sides, up to the tips of the transverse processes. For the thoracic spine, the soft tissues on the facet joints were thoroughly cleaned off to ensure better visualization of the bony landmarks. The drill template was then placed on the spinous, lamina, and transverse processes. The drill template and the corresponding spinous process were fitted well. A high-speed drill was used along the navigational channel to drill the trajectory of each pedicle screw. Using a hand drill, the trajectory of the pedicle screw was carefully drilled to a depth in accordance with the pre-operation plan. The pedicle screw, the diameter and length of which had been chosen pre-operatively, was carefully inserted along the same trajectory. After screw placement and correction of deformity, all exposed laminar surfaces were decorticated, and the autologous iliac crest bone was grafted.

A total of 168 screws were placed from T2 to T12 in the 16 cases, and post-operative CT scans were obtained in all 16 patients. About 157 screws were considered intrapedicular, while 11 screws were considered to have a 0-2 mm breach (1 medial, 10 lateral in which 8 belonged to the planned in-out-in screws). No pedicle screw breached more than $2 \mathrm{~mm}$, and the overall screw accuracy ( $<2 \mathrm{~mm}$ breach is safe) was $100 \%$. No screws penetrated the inferior or superior cortex in the sagittal plane.

\subsubsection{A Novel Patient-specific Navigational Template for laminar Screw Placement}

Instability of the occipitocervical junction requiring surgical stabilization may be treated with a variety of techniques. The objective is to obtain solid fusion of the involved segments, which is best achieved by minimizing motion between them. Older methods such as the Brooks-Jenkins or modified Gallie wiring techniques, are simpler procedures, have been known for a long time and are associated with failure rates of fusion up to $25 \%$, primarily in cases with rotational instability. Newer techniques have been described that effectively limit 


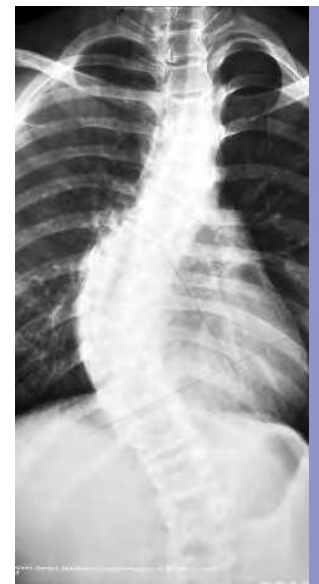

(a)

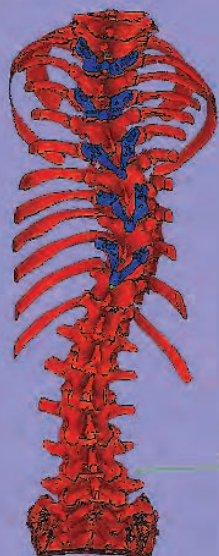

(b)

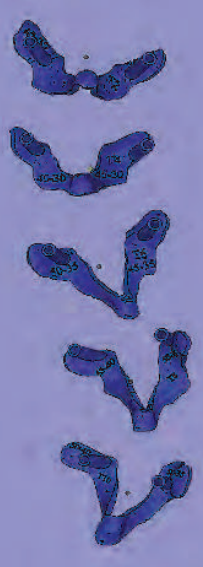

(c)

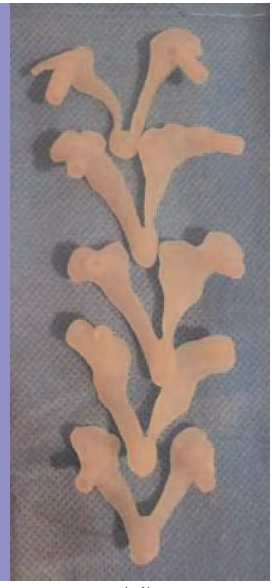

(d)

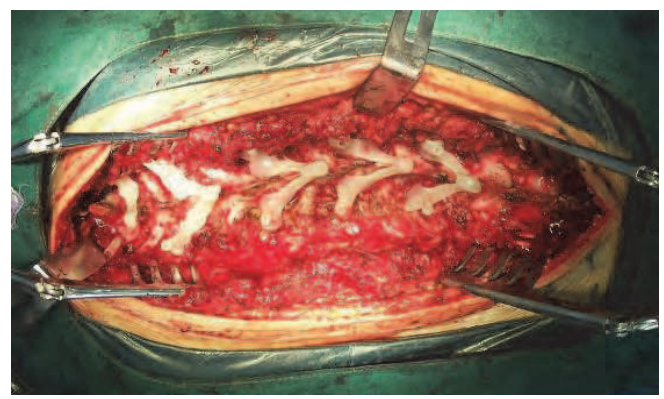

(e)

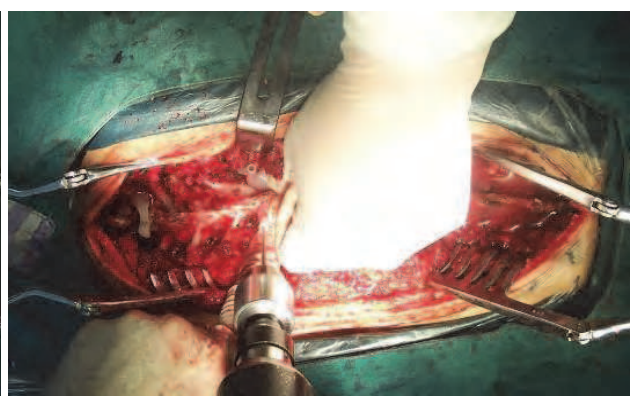

(f)

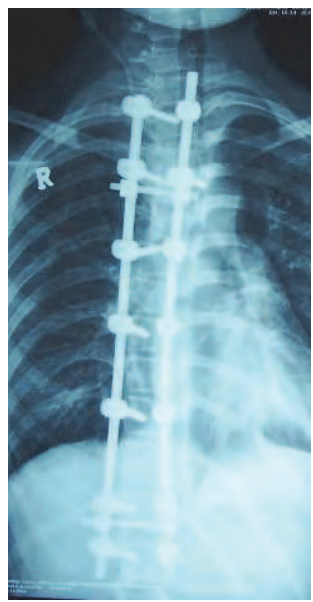

(g)

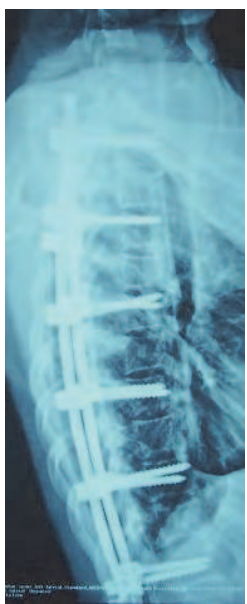

(h) 


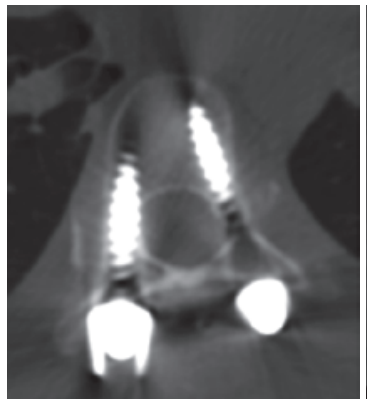

(i)

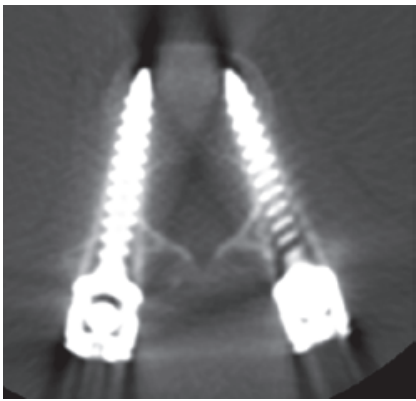

(j)

Fig. 8. A 12 -year-old male with a $62^{\circ}$ pre-operative curve; thoracic pedicle screw was inserted using the drill template;

a: AP X-ray; b: 3-D model of the spine; c: Pedicle screw trajectory and design of the navigational template; $\mathrm{d}$ : RP model of the navigational template, $\mathrm{e}$ : The navigational template fits the posterior part of the thoracic perfectly in the operation; $\mathrm{f}$ : Drill the trajectory by a power drill. g, $\mathrm{h}, \mathrm{I}, \mathrm{j}$ : $\mathrm{X}$ ray and $\mathrm{CT}$ scan show that the screws were fully contained within the pedicle and body; corrected to $11^{\circ}$ one year after surgery, giving $82.3 \%$ correction of the major curve.

motion along all axes. The addition of transarticular screw fixation, according to Magerl and Seemann, offers a better biomechanical stability. But, Magerl screw fixation must be very precise point of placement to make screw fixation in the lateral mass of atlas, this can result in a significant risk to the vertebral artery. The size of the C2 pedicle can limit the ability to safely place these screws, particularly taking into account the anomalous position of the vertebral artery in relation to the isthmus of C2 in up to $20 \%$ of the population. Leonard and Wright [7] described a new technique of C2 laminar screw for rigid screw fixation of the axis and incorporation into atlantoaxial fixation or subaxial cervical constructs, and subsequent cases have shown good clinical results with this technique. C2 laminar screws are appealing due to the reduced risk of injury to the vertebral artery and biomechanical stability. The present method of C2 laminar screw placement relies on anatomical landmarks for screw placement. Placement of C2 laminar screws using drill template has not been described in the literature. A novel computer- assisted drill guide template for placement of C2 laminar screws, Which designed to simplify and shorten the surgical act and at the same time further enhance the accuracy of screw positions in the $\mathrm{C} 2$ laminar.

Before the operation, a spiral three-dimensional (3-D) CT scan (LightSpeed VCT, GE, USA) was performed on cervical spine of each patient with $0.625-\mathrm{mm}$ slice thickness and $0.35-\mathrm{mm}$ in-plane resolution. The images were stored in DICOM format, and transferred to a workstation running MIMICS 10.01 software (Materialise company, Belgium) to generate a 3$\mathrm{D}$ reconstruction model for the desired C2 vertebrae (Fig. 9a). The 3-D vertebral model was then exported in STL format, and opened in a workstation running Reverse Engineering (RE) software UG imageware12.0 (EDS, USA) for determining the optimal screw size and orientation. A screw with a diameter of $4 \mathrm{~mm}$ was placed virtually into the 3-D spinal model on both sides. The virtual screw's entry point and the trajectory was placed centered on the lamina without violating the cortex and two screws will not interfere with each other. (Fig. 9b). The optimal screw size was determined according to the size of laminea as well. Afterwards, a navigational template was constructed with one drill guide on either side. The template 
surface was created to be the inverse of C2 spinous process and laminar, thus potentially enabling a fit in a lock-and-key fashion similar to a physical casting of the vertebral surface, and specifically avoided overlap onto adjacent segments (Fig. 9c). The inner diameter of the hollow cylinder was created to accommodate the preplanned trajectory for drilling. Once these had been done, a drill template was constructed with a surface designed to be the inverse of the vertebral surface (Fig. 9d).

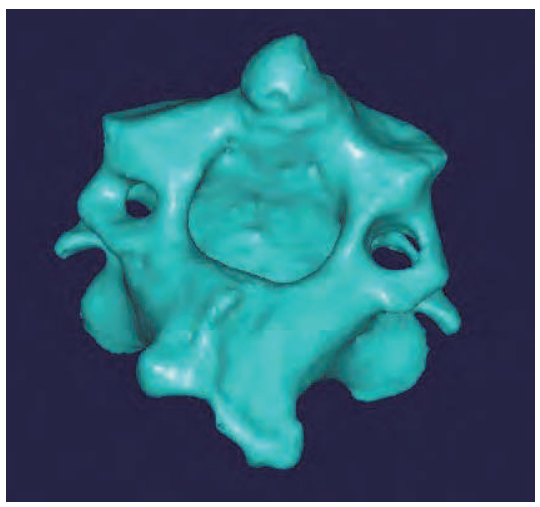

(a)

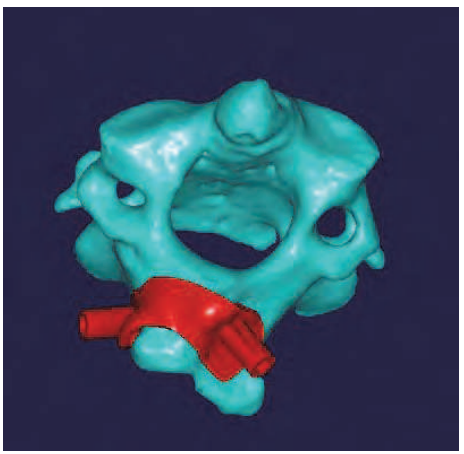

(c)

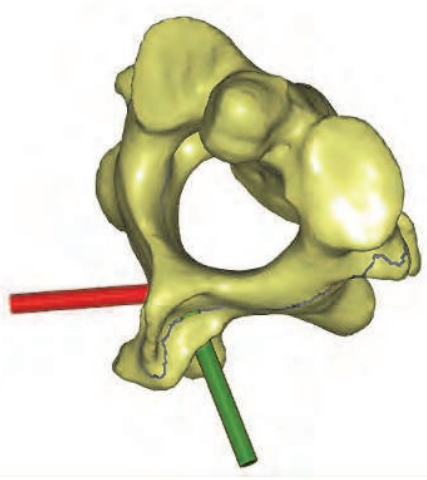

(b)

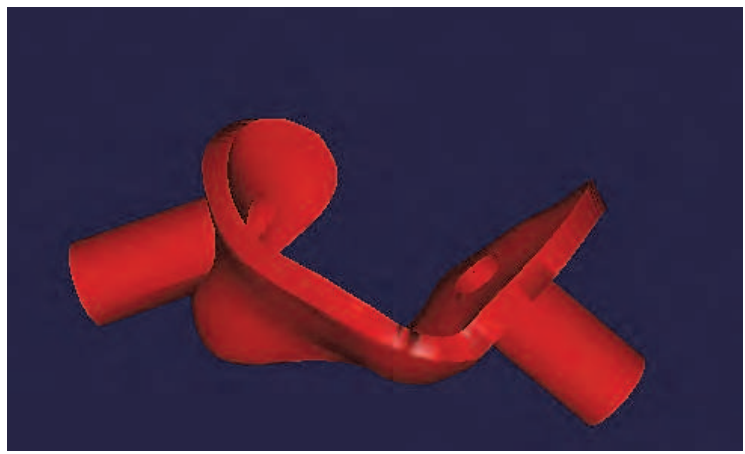

(d)

Fig. 9. The design of the virtual navigational template

a: 3-D model of C2 vertebra; b: virtual display of the planned laminar screw trajectory; c: navigational template fit the vertebral perfectly; $d$ : The virtual 3-D model of navigational template

The computer model was then exported in STL format. The biomodel of the C2 vertebra as well as its corresponding navigational template were both produced by acrylate resin (Somos 14120, DSM Desotech Inc, USA) using stereolithography rapid prototyping (RP) technique. The accuracy of the navigational template was before surgery examined by visual inspection. The biomodel and its coresponding template were placed together, and a standard electric power drill was used to drill screw trajectory into the biomodel at the predefined placement, and visual inspection was taken for any violation of C2 laminar (Fig. 10). 


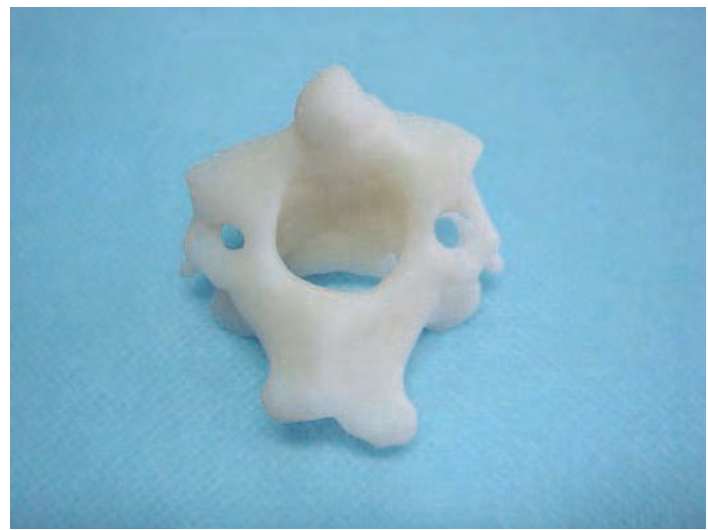

(a)

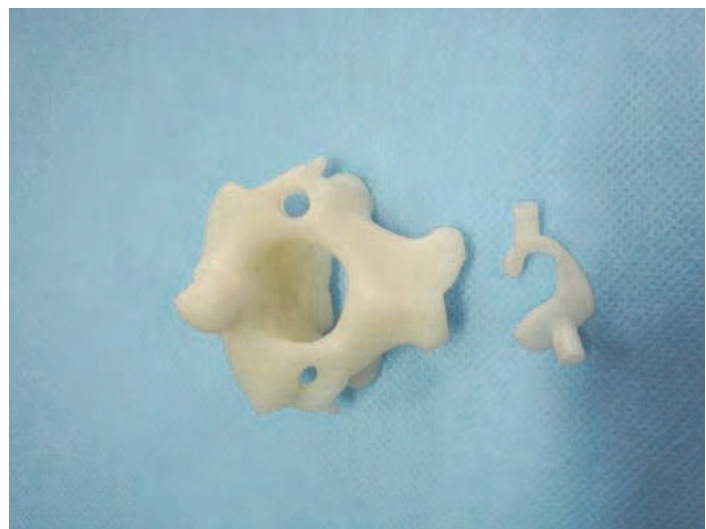

(b)

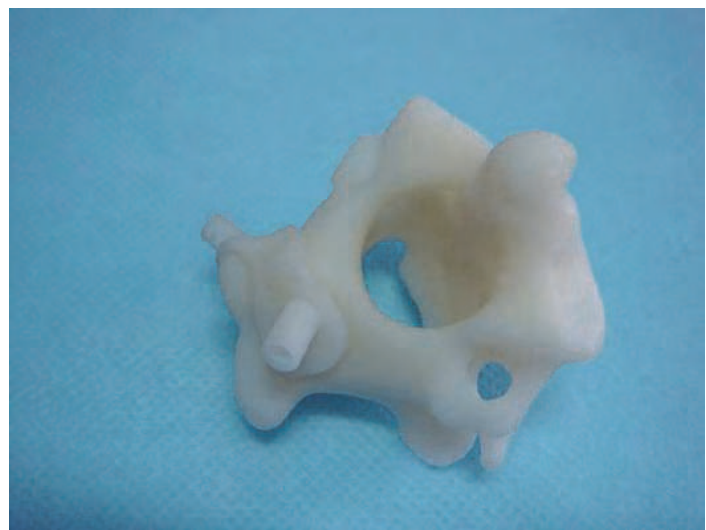

(c) 


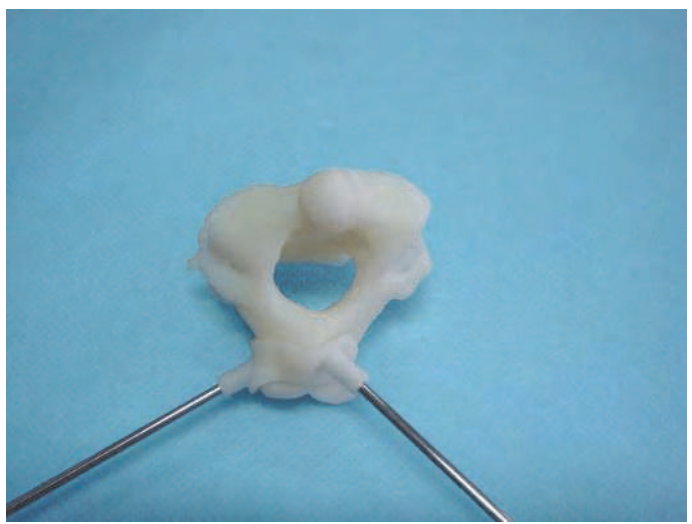

(d)

Fig. 10. The accuracy of the navigational template was examined by visual inspection a: RP model of C2 vertebra; b: RP model of C2 vertebra and navigational template; c: navigational template fit RP model of vertebra perfectly; $d$ : insert the $\mathrm{K}$ wire by navigational template; the accuracy of the navigational template was examined by visual inspection.

From June 2006 to Septempber 2008, 9 patients (four males, five females, age 17-53 years) with basilar invagination requiring the posterior instrumentation were performed occipitocervical fusion surgery by $\mathrm{C} 2$ laminar screw fixation. There are eight cases with occipitalization of the atlas, six cases accompanied by $\mathrm{C} 2-\mathrm{C} 3$ vertebral fusion. In three patients a transoral surgery was performed firstly, followed by posterior surgery. The anatomy of $\mathrm{C} 2$ pedicle was observed preoperative $\mathrm{X}$ ray and $\mathrm{CT}$ scan, if the pedicle is very narrow, thin, or vertebral artery high riding, it would be inappropriate placement of pedicle screw, the laminea screw fixation can be choosed.

Tracheal intubation using general anesthesia, patients are placed in the prone position with the head and cervical spine maintained in the neutral position using the Mayfield head holder. The spinous process, laminae and lateral masses of of C2 are then exposed as needed. Then the drill template was placed on the spinous process and laminae of C2. Template and the corresponding spinous process were fitted well. The high-speed drill is used along the navigational channel to drill the trajectory of laminar screw. Using a hand drill, the trajectory of laminar screw is carefully drilled to a depth of preoperation plan. A $4.0 \mathrm{~mm}$ screw is carefully inserted along the same trajectory. Using the same technique as above, a $4.0 \mathrm{~mm}$ screw is placed into the other lamina. After screw placement, all exposed laminar surfaces are decorticated with the high-speed drill. Autologous iliac crest bone grafts are wedged under the rods between the occipital bone and the spinous process and lamina of $\mathrm{C} 2$.

Using the virtual 3-D model, the optimal entry point for the bore can be choosed, thus determining the entry point and direction for the $\mathrm{C} 2$ laminar screw. The drill template was created to fit the postural surface of $\mathrm{C} 2$ spinous process very well. The accuracy of the drill template was before operation examined by drilling $\mathrm{K}$ wire trajectory into the vertebra biomodel. Each navigational template fits its corresponding vertebral biomodel perfectly, and $\mathrm{K}$ wire was found to be inserted through the drill hole into the $\mathrm{C} 2$ lamina, no violation was found by visual inspection.

Nine patients with basilar invagination were performed occipitocervical fusion surgery, the bilateral cross laminar screw fixation was preformed in eight patients, unilateral laminar 
screw fixation and other side of pedicle screw fixation was preformed in a patient. Average follow-up was 9 months (range 4-13 months). Preoperative and postoperative functional comparisons were made using the ASIA grading scale for all cases. Seven Of the patients $(77.8 \%)$ improved at least one ASIA grade. Two patients have not improve. No patient suffered neurological deterioration as a result of the procedure.

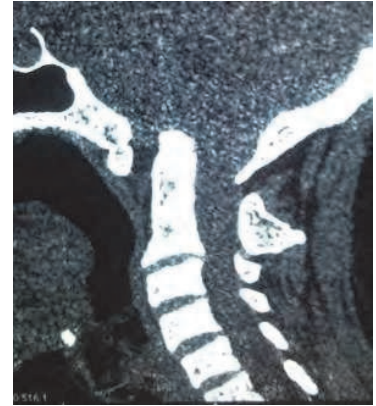

(a)

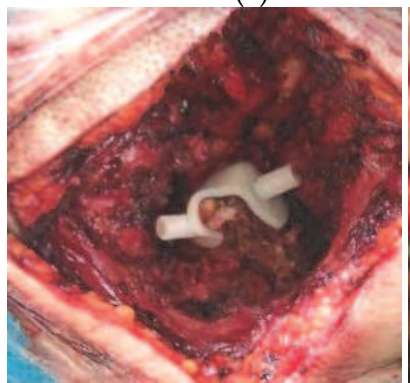

(d)

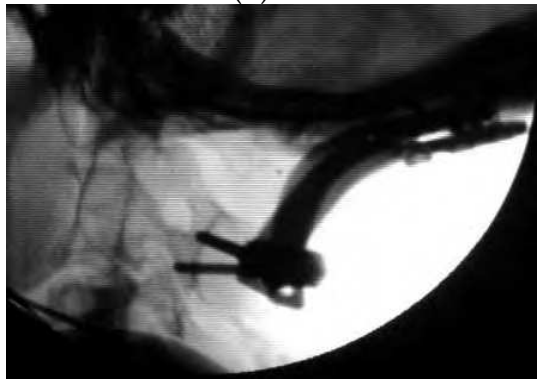

(g)

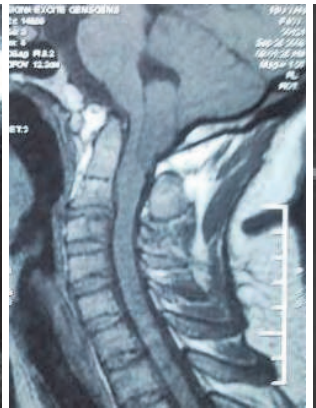

(b)

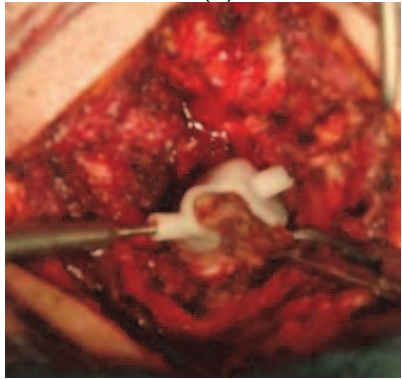

(e)

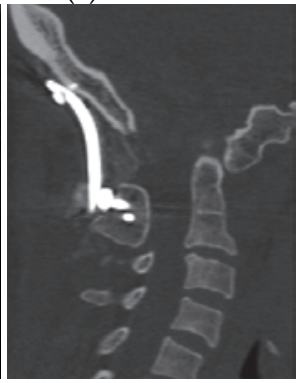

(h)

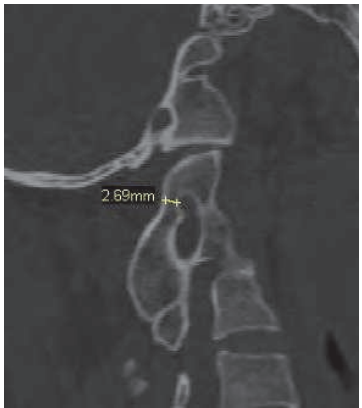

(c)

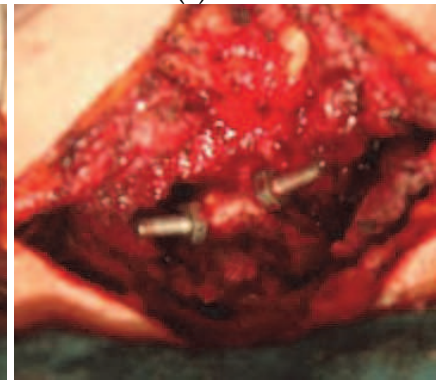

(f)

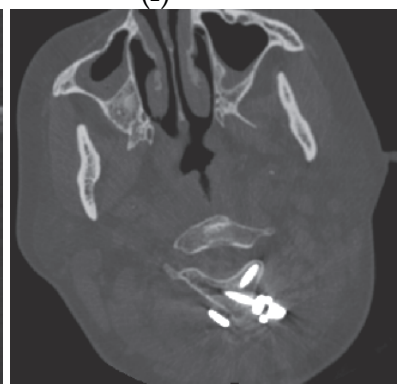

(i)

Fig. 11. The navigational template applied in the operation of a 42- year- old women with basilar invagination, occipitalization of the atlas and C2- $\mathrm{C} 3$ vertebral fusion.

$\mathrm{a}, \mathrm{b}$ : Pre-operative CT and T1 sagittal MRI displaying ventral brainstem compression; c: Preoperation CT show the pedicle of C2 is narrow and can not accommodate the $3.5 \mathrm{~mm}$ pedicle screw; d: Navigational template fit the spinous process and lamina of C2 perfectly; e: The high-speed drill is used along the navigational channel to drill the trajectory of laminar screw; f: Insert the cervical pedicle screw by navigational template; $g, h, i$ : Postoperative CT showing accurate placement of C2 laminar screws 
Seventeen C2 laminar screws were inserted using drill emplate. No screw inserted complications such as spinal cord, nerves, vertebral artery injury appear in this group. The mean operative time between fixation of the template to the lamina and placement of the screw was 1 to 2 minutes. Operation time reduced through use of the navigational template. No additional computer assistance was needed during surgery, and fluoroscopy was used only once, after all the C2 laminar screws had been inserted. The method thus significantly reduced radiation exposure for the members of the surgical team.

It takes about 16 hours to manufacture the RP model, and the price of each RP model of the vertebra and navigational template is about $\$ 20$. Postoperative CT scans showed that the individual template has a higher precision. No laminar screw misplacement occurred using the individual template. (Fig. 11)

\subsection{Design and primary application of computer-assisted, patient-specificnavigational templates in metal-on-metal hip resurfacing arthroplasty}

Total hip resurfacing arthroplasty, viewed by many as representing an evolution from the mold arthroplasty procedure of Smith-Petersen, has been considered an alternative to total hip arthroplasty for adult patients with osteoarthritis of the hip or congenital hip dysplasia. It has been performed with a variety of materials, designs, surgical approaches, techniques, and fixation methods [1]. Many advantages of hip resurfacing arthroplasty have been suggested, including bone conservation [2-4], improved function as a consequence of retention of the femoral head and neck and more precise biomechanical restoration [5], decreased morbidity for revision arthroplasty [6], reduced dislocation rates [7,8], and normal femoral loading and reduced stress shielding [9]. In hip resurfacing arthroplasty, prosthesis location is key to postoperative joint stability. In conventional hip arthroplasty, the neck-shaft angle is determined by the design of the prosthesis itself, whereas in hip resurfacing, it is determined by valgus or varus placement of the femoral prosthesis. When the prosthesis is inserted by conventional positioning, some positioning devices are needed; however, accuracy cannot always be achieved with current devices. Successful positioning thus depends largely on how experienced the surgeon is. With the development of computer-aided design and computer-aided engineering, the trend in medical technology has been toward individualization. We conducted a study in which we introduced and validated novel locating navigation templates in the clinical setting. The templates' designs are based on reverse engineering. The patient-specific design allows close contact with acetabular and femoral features to provide better stability and function than is possible with conventional positioning devices.

Three-dimensional (3-D) computed tomography (CT) pelvic scan image data were obtained from 10 healthy volunteers who underwent a spiral 3-D CT scan (Light- Speed VCT; GE, Fairfield, CT) using a $0.625-\mathrm{mm}$ slice thickness and $0.35-\mathrm{mm}$ in-plane resolution. Data were transferred via a digital imaging and communications in medicine network into a computer workstation. Three dimensional models of the hips were reconstructed using Amira software (version 3.1; TGS, San Diego, CA) and saved in stereolithography format. The 3-D models were then imported into Imageware software (version 12.0; EDS, Palo Alto, CA). First, data for the transaction planes (1-mm thickness) of the acetabular and femoral head surfaces were extracted; and the correctly fitting globe was produced. The globe center was considered to be the rotation center of both the acetabulum and the femoral head. Second, we presumed an ideal acetabular location of about $45^{\circ}$ abduction and $18^{\circ}$ anteversion and 
an optimum location for the femoral head implant of $140^{\circ}$ abduction along the axis of the femoral neck. Finally, we designed specific navigation templates according to the anatomical features of the acetabular contour and the femoral head (Figs. 12 and 13).

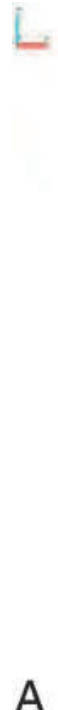

A

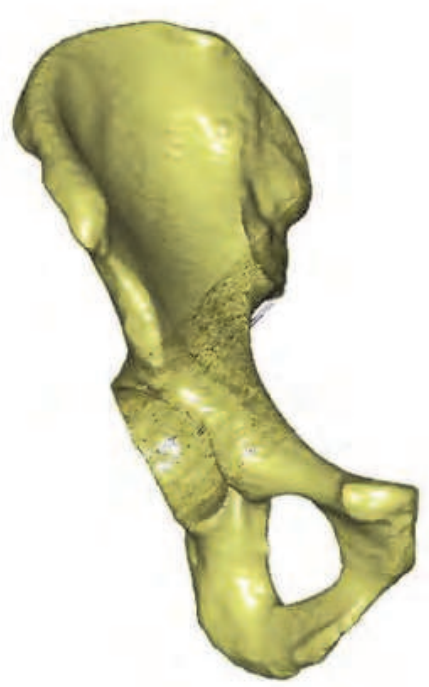

C
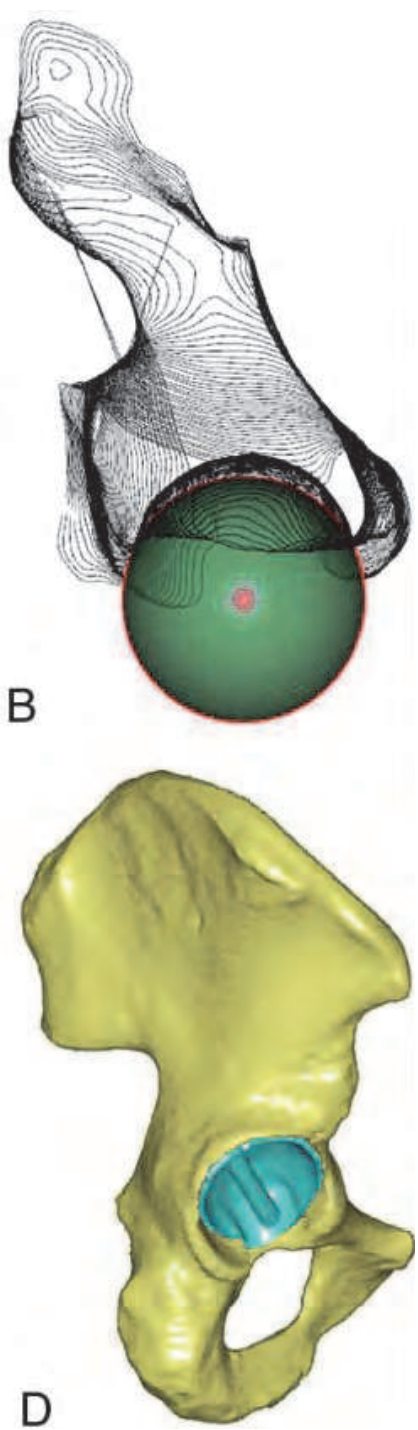

Fig. 12. Determination of the rotation center and the design process for a navigation template for the acetabulum: (A) preparing a 3-D reconstruction of the hip and dissection of acetabular surface, (B) constructing the rotation center of the acetabulum (small ball), (C) determining the navigation channel, and (D) producing the navigation template. 
A
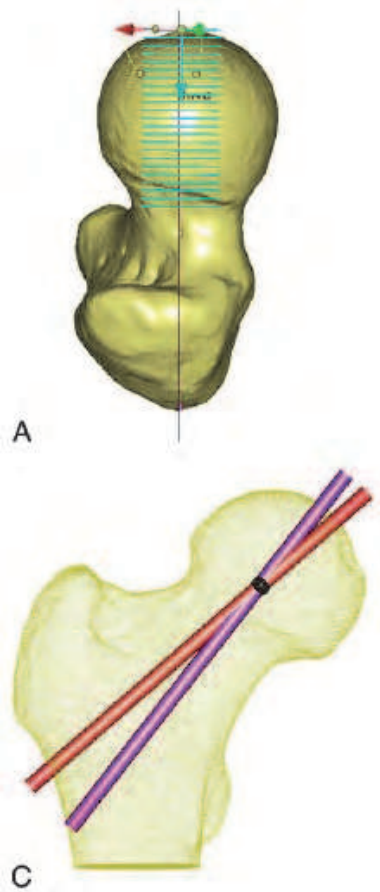
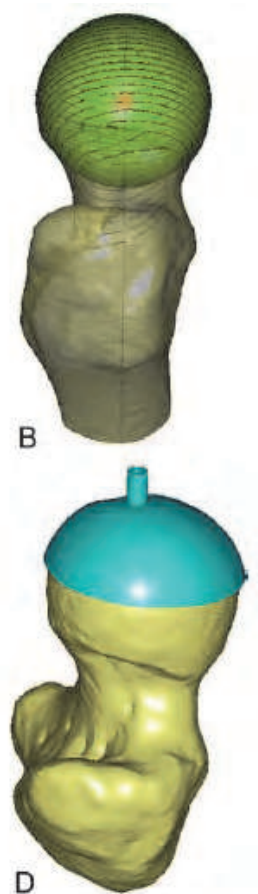

Fig. 13. The design process for a femoral head navigation template: (A) determining the axial ray on the femoral neck and dissecting the femoral head, (B) constructing the center of femoral head (small ball), (C) determining the navigation channel, and (D) producing the navigation template.

20 patients (11 men and 9 women) with pathologic changes in one hip who were 24 to 37 years old were scheduled for total hip resurfacing arthroplasty. They were randomly assigned to undergo either conventional implantation of a prosthesis (control group) or implantation of a prosthesis guided by navigation templates (NT group). The navigation templates were made as described in the preceding section. Navigation template models were exported in stereolithography format and formed from acrylate resin (Somos 14120;DSMDesotech Inc, Stanley, NC) using the stereolithography rapid prototyping (RP) technique (Fig. 14).
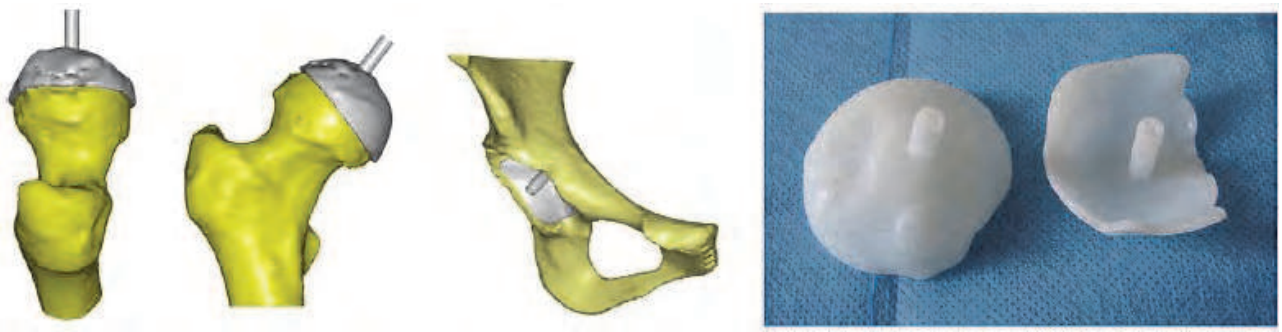

Fig. 14. Template models of the acetabulum and femoral head. 
Duration of surgery and intraoperative blood loss for the 2 groups were compared. Deviation between the ideal abduction angles and the actual angles of the implanted acetabular cup was calculated, as was deviation of cup anteversion angles. The deviation between the neck-shaft angle and the actual implanted short stem-shaft angle (SSA) and that between the anteversion angle of the femoral neck and the anteversion angle of the actual implanted short stem were measured. Angle deviations in the NT group were compared with those in the control group. In the NT group, after dislocation of the hip and insertion of the template into the acetabulum, a 3.2-mm-diameter guide pin was placed in the template hole. We followed the guide pin with the acetabular reamer to drill and shape the prosthetic socket at $45^{\circ}$ abduction and $18^{\circ}$ anteversion.
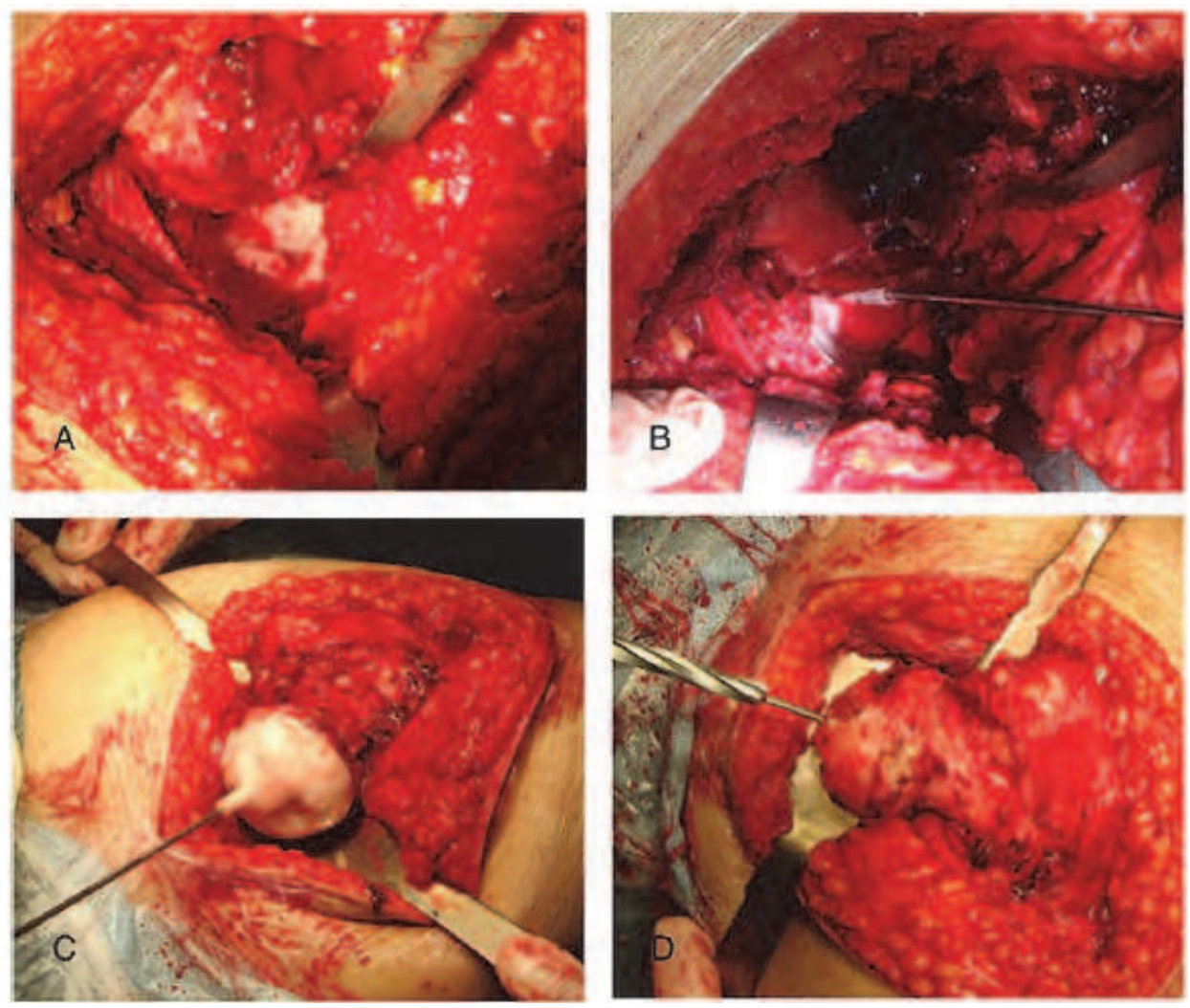

Fig. 15. Surgical procedure in the navigation template group: (A) locating the acetabulum, (B) inserting a guide pin, (C) matching the navigation template and inserting a Kirschner wire, and (D) enlargement canals.

When the femoral head was dislocated and correctly exposed, we matched the locating template to the surface of the femoral head as well as possible. We then inserted a Kirschner wire into the femoral neck according to the template. We evaluated the axial location of the femoral component (shown by the Kirschner wire) with anteroposterior (AP) and lateral position photographs obtained during surgery by a $C$ arm machine (Fig. 15). We obtained 
radiographs for all patients at some point between 7 and 10 days after surgery. Radiographic analysis included an AP view of the pelvis and AP and lateral views of the hip. On AP radiographs, the SSA was measured between the axial line of the femur and the extension line of the component stem with a measuring tool from Adobe Photoshop software (version 7.0; Adobe, San Jose, CA).

The navigation templates were found to be highly accurate (Fig. 16). The average duration of surgery for the NT group was 118.6 minutes vs 140.2 minutes for the control group (P b .05). The average intraoperative blood loss in NT group was $410.9 \mathrm{~mL}$ vs $480.6 \mathrm{~mL}$ for the control group ( $\mathrm{P} \mathrm{b} .05)$. The average deviation of the cup abduction angle $\left(1.2^{\circ} \pm 0.9^{\circ}\right)$ was significantly less in the NT group than in the control group $\left(5.4^{\circ} \pm 3.2^{\circ}, \mathrm{P} \mathrm{b} .05\right)$, and the average deviation of the cup anteversion angle $\left(2.1^{\circ} \pm 1.2^{\circ}\right)$ was significantly less in the NT group than in the control group $\left(4.1^{\circ} \pm 2.8^{\circ}, \mathrm{P} \mathrm{b} .05\right)$. In addition, the average deviation of the femoral SSA $\left(1.3^{\circ} \pm 1.0^{\circ}\right)$ was significantly less in the NT group than in the control group $\left(10.2^{\circ} \pm 1.5^{\circ}, \mathrm{P} \mathrm{b} .05\right)$.
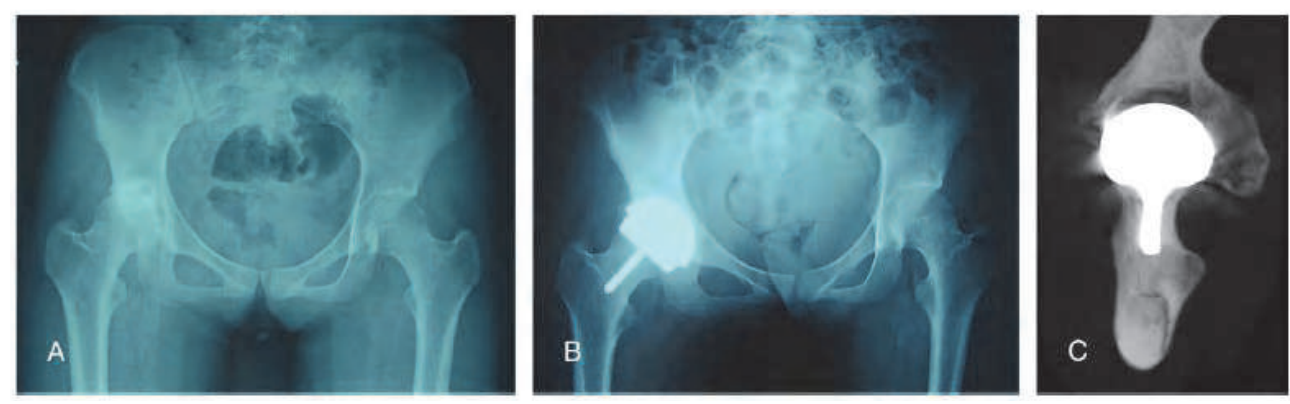

Fig. 16. (A) Anteroposterior radiograph of a patient from the navigation template group shows hip pathology before surgery. (B, C) Anteroposterior radiograph and computed tomography image from the same patient show prosthesis position after surgery.

\section{Conclusion}

The authors have developed a novel patient-specific navigational template for spinal pedicle screw placement, placement of C2 laminar screws, and accurate prosthesis implantation in hip resurfacing arthroplasty with good applicability and high accuracy. The potential use of navigational templates in orthopedics surgery is promising. Our methodology appears to provide an accurate technique and trajectory for orthopedics surgery.

\section{Acknowledgment}

This work was supported by Yunnan Natural Science Foundation (2008CD210 and 2010ZC183).

\section{References}

[1] Lu S, Xu YQ, Zhang YZ, Li YB, Xie L, Shi JH, Guo H, Chen GP, Chen YB.(2009) A novel computer-assisted drill guide template for lumbar pedicle screw placement: a cadaveric and clinical study. Int J Med Robotics Comput Assist Surg, 5(2): 184-191 
[2] Sheng Lu, Yong Q. Xu, William W. Lu, Guo X. Ni, Yan B. Li, Ji H. Shi, Dong P. Li, Guo P. Chen, Yu B. Chen and Yuan Z. Zhang. (2009) A Novel Patient-Specific Navigational Template for Cervical Pedicle Screw Placement. SPINE, 34(26):E959-E964.

[3] Sheng Lu, Yong Q. Xu, Yuan Z. Zhang, Le Xie, Hai Guo, Dong P. Li. (2009) A novel computer-assisted drill guide template for placement of C2 laminar screws. Eur Spine J, 18(9):1379-1385.

[4] Richter M, Cakir B, Schmidt R.(2005) Cervical pedicle screws: conventional versus computerassisted placement of cannulated screws. Spine, 30: 2280-2287.

[5] Kotani Y, Abumi K, Ito M, Minami A. (2003) Improved accuracy of computer-assisted cervical pedicle screw insertion. J Neurosurg, 99:257-263.

[6] Lonner BS, Auerbach JD, Estreicher MB, et al. (2009) Thoracic pedicle screw instrumentation: the learning curve and evolution in technique in the treatment of adolescent idiopathic scoliosis. Spine, 34:2158-64

[7] Leonard JR, Wright NM (2006) Pediatric atlantoaxial fixation with bilateral, crossing C-2 translaminar screws. Technical note. J Neurosurg, 104:59-63 


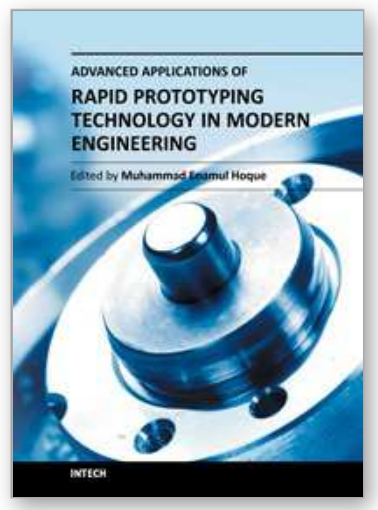

\section{Advanced Applications of Rapid Prototyping Technology in Modern Engineering}

Edited by Dr. M. Hoque

ISBN 978-953-307-698-0

Hard cover, 364 pages

Publisher InTech

Published online 22, September, 2011

Published in print edition September, 2011

Rapid prototyping (RP) technology has been widely known and appreciated due to its flexible and customized manufacturing capabilities. The widely studied RP techniques include stereolithography apparatus (SLA), selective laser sintering (SLS), three-dimensional printing (3DP), fused deposition modeling (FDM), 3D plotting, solid ground curing (SGC), multiphase jet solidification (MJS), laminated object manufacturing (LOM). Different techniques are associated with different materials and/or processing principles and thus are devoted to specific applications. RP technology has no longer been only for prototype building rather has been extended for real industrial manufacturing solutions. Today, the RP technology has contributed to almost all engineering areas that include mechanical, materials, industrial, aerospace, electrical and most recently biomedical engineering. This book aims to present the advanced development of RP technologies in various engineering areas as the solutions to the real world engineering problems.

\section{How to reference}

In order to correctly reference this scholarly work, feel free to copy and paste the following:

Sheng Lu, Yong-qing Xu and Yuan-zhi Zhang (2011). Application of a Novel Patient - Specific Rapid Prototyping Template in Orthopedics Surgery, Advanced Applications of Rapid Prototyping Technology in Modern Engineering, Dr. M. Hoque (Ed.), ISBN: 978-953-307-698-0, InTech, Available from: http://www.intechopen.com/books/advanced-applications-of-rapid-prototyping-technology-in-modernengineering/application-of-a-novel-patient-specific-rapid-prototyping-template-in-orthopedics-surgery

\section{INTECH}

open science | open minds

\section{InTech Europe}

University Campus STeP Ri

Slavka Krautzeka 83/A

51000 Rijeka, Croatia

Phone: +385 (51) 770447

Fax: +385 (51) 686166

www.intechopen.com

\section{InTech China}

Unit 405, Office Block, Hotel Equatorial Shanghai

No.65, Yan An Road (West), Shanghai, 200040, China

中国上海市延安西路65号上海国际贵都大饭店办公楼405单元

Phone: +86-21-62489820

Fax: $+86-21-62489821$ 
(C) 2011 The Author(s). Licensee IntechOpen. This chapter is distributed under the terms of the Creative Commons Attribution-NonCommercialShareAlike-3.0 License, which permits use, distribution and reproduction for non-commercial purposes, provided the original is properly cited and derivative works building on this content are distributed under the same license. 